\title{
CONTA PETRÓLeO e A BALANÇA COMERCIAL BRASILEIRA: \\ UMA ANÁLISE DO PERÍODO RECENTE
}

\author{
REISOLI BENDER FILHO
}

\section{RESUMO}

O resultado comercial brasileiro vem se deteriorando nos anos recentes, com um peso crescente do déficit da denominada conta petróleo. Buscando subsidiar a discussão sobre esse tema, o estudo examinou a conta petróleo, como também a sua relação com a balança comercial brasileira, entre 2000 e 2014. Os resultados permitiram sugerir que a relação não se mostrou estável ao longo do período analisado, ao passo que a influência mais expressiva do saldo da conta petróleo sobre o saldo comercial brasileiro verificou-se após 2007, posteriormente à crise econômica internacional, intensificando-se nos últimos anos. A partir desse período, o comportamento volátil da conta petróleo, consubstanciado no agravamento do saldo negativo, em alguma medida, tem sido absorvido pela balança comercial do país, em um efeito transferência.

Palavras-Chave: conta petróleo, balança comercial, economia brasileira.

\section{ABSTRACT}

In the recent years, Brazilian's business outcome has being deteriorating, with a growing deficit for the so-called petrol account. In an effort to subsidize the discussion of this issue, this study proposed to investigate the petrol account, as well as its relation with Brazilian's trade balance between 2000 and 2014. The results allowed the suggestion that the relation discussed has not been stable during the long term period analyzed, while the most significant influence of the balance of petroleum account on the Brazilian commercial balance has been verified after 2007, in the aftermath of the international economic crisis, and has been intensified in the recent years. After this period, the volatile behavior of petroleum account, embodied in the worsening of its deficit, in a way, has been absorbed by the country's commercial balance, in a transferring way.

KEYWORDS: petroleum account, trade balance, Brazilian economy.

\section{INTRODUÇÃo}

O saldo comercial nos anos recentes tem repercutido de forma cada vez mais expressiva sobre o resultado das transações correntes brasileiras. Essa condição é resultado da ampliação do comércio internacional, decorrente do crescimento a taxas elevadas da economia (demanda) mundial, com destaque para a China. Na esteira desse cenário, associado ao excesso de liquidez no sistema financeiro internacional (Bello, 2010), observou-se a crescente elevação dos preços das diferentes commodities exportadas pelo país. 
Esses fatores determinaram que as transações correntes brasileiras se mantivessem superavitárias até 2007 , situação que se verificava desde o início dos anos 2000 , coincidindo com a trajetória crescente da balança comercial, que havia atingido o valor máximo no ano anterior. Nos anos seguintes, a conta-corrente passou a apresentar resultados negativos, ao mesmo tempo em que a balança comercial, embora positiva, iniciou uma trajetória declinante, situação que se acentuou em 2014, quando o resultado das transações comerciais externas foi negativo em cerca de US $\$ 4$ bilhões.

Esse processo de deterioração das contas externas brasileiras, a despeito do crescimento dos preços e dos termos de troca, deve-se ao exponencial crescimento das importações, as quais entre $2007 \mathrm{e}$ 2014 se expandiram acima de $8,4 \%$ ao ano, enquanto as exportações se elevaram em aproximadamente 4,4\%. Tal cenário era antagônico na primeira metade da década (2000-2006), haja vista que o crescimento das exportações foi praticamente o dobro daquele verificado nas importações (IBP, 2015).

Porém, argumentar-se-ia que o cenário negativo das contas externas brasileiras sofreu influência da crise econômica internacional. Entretanto, embora a crise tenha afetado praticamente todas as economias, não foi um fenômeno generalizado, tanto em termos de efeitos quanto em condições de recuperação (Brum, 2013), em que pese o crescimento das exportações nacionais nos anos pós-crise, exceto em 2009 , ter sido substancialmente inferior ao das exportações mundiais.

Conquanto sejam diversos os argumentos discutidos para a retração da balança comercial brasileira, entre eles tem ganhado supremacia o resultado das importações e exportações de petróleo e derivados, a denominada conta petróleo ${ }^{1}$. Justifica-se essa problematização, dado que as importações desses produtos cresceram de forma contínua, com maior velocidade nos últimos dez anos, atingindo em alguns períodos o equivalente a um quinto do total importado pelo país; por sua vez, as exportações se expandiram, porém mais moderadamente, e participam com menos de $10 \%$ do total exportado. Daí a sugestão de que esses resultados têm acentuado o déficit comercial da conta petróleo, com possíveis impactos sobre o saldo comercial brasileiro.

Procurando subsidiar essa discussão, o estudo se propôs a examinar a conta petróleo, como também a relação desta com a balança comercial brasileira, no período recente (2000-2014). Particularmente, têm-se como objetivos analisar (i) o comportamento dos fluxos comerciais do petróleo e derivados (importações e exportações), discutindo sua evolução e os fatores a ela associados, e (ii) os efeitos do recorrente déficit da conta petróleo sobre o resultado da balança comercial.
[1] Tecnicamente, a conta petróleo foi instituída na década de 1960 e consistia na equalização dos preços dos derivados de petróleo no território nacional. Posteriormente, a conta passou a servir a outros fins, sendo o principal deles o tabelamento ou subsídio ao preço dos combustíveis no mercado doméstico. A lei 9.478 , de 1997, conhecida como Lei do Petróleo, definiu que, após um período de transição, os preços dos combustíveis passariam a ser livres em toda a cadeia, o que significaria o fim dos subsídios. No entanto, como parte da transição, em 1998 foi criada a Parcela de Preço Específica, que gerava créditos para a conta petróleo e que serviu para diversos fins, como o financiamento dos subsídios cruzados, os subsídios do álcool e os subsídios ao transporte em regiões remotas. Além disso, a parcela passou a servir como amortecedor das eventuais flutuações no mercado internacional de petróleo. Somente em dezembro de 2001 ocorreu a liberação completa dos preços dos combustíveis. 
[2] Sendo os recursos obtidos com as exportações, não há compromissos de gastos futuros, enquanto aqueles originários de empréstimo ou de investimentos no país podem acarretar posteriormente pagamentos como juros ou cortar remessa de lucros, $e$, quando derivam de empréstimos em moeda, ainda terão de ser amortizados futuramente (Bello, 2010).
A relação estabelecida, de dependência ou de complementaridade, entre os fluxos de comércio do petróleo e o resultado comercial brasileiro historicamente se mostra relevante, haja vista a importância do setor de combustíveis para o país, sendo inclusive utilizado como sustentáculo de políticas econômicas de crescimento e de estabilização. Logo, o aprofundamento dessa discussão constitui-se na principal diretriz do trabalho, além de contribuir para a discussão em um campo ainda incipiente, visto o número reduzido de estudos sobre essa temática encontrados na literatura.

Além desta introdução, o estudo compreende outras quatro seções. Na segunda seção discutem-se a balança comercial brasileira e sua evolução. A terceira discute o comportamento da conta petróleo, com destaque para os resultados comerciais e sua relação com a balança comercial. E a última traz as principais conclusões e apontamentos acerca da temática discutida.

\section{A BALANÇA COMERCIAL BRASILEIRA NOS ANOS RECENTES}

O resultado comercial brasileiro tem se mostrado de relevância ímpar nos anos recentes, sobremaneira por seu comportamento indicar a capacidade da atividade doméstica, tanto quando considerada a produção quanto quando considerado o consumo, além de se refletir diretamente no saldo de transações correntes e, consequentemente, na forma de seu financiamento. Conforme Bello (2010), há implicações importantes para a forma de financiamento, quando considerada a fonte dos recursos, se oriundos da balança comercial ou da balança de capitais ${ }^{2}$.

O início dos anos 2000 marcou a retomada de saldos positivos da balança comercial brasileira, depois de seis anos consecutivos de déficit (1995-2000), período em que o resultado negativo acumulado das relações de comércio (exportações e importações) somou US $\$ 24,5$ bilhões. Concorreu para esse cenário o fato de a quantidade exportada ter crescido aproximadamente $26 \%$, ao passo que o quantum das importações se expandiu em mais de $80 \%$.

A evolução das exportações e das importações e o respectivo resultado dessas operações, a balança comercial, para o período que se segue aos anos 2000 encontram-se na Figura 1 e subsidiaram as discussões acerca das particularidades das relações comerciais brasileiras. 
Figura 1

Exportações, importações e balança comercial brasileira, entre janeiro/2000 e fevereiro/2015, em US\$ milhões (FOB)

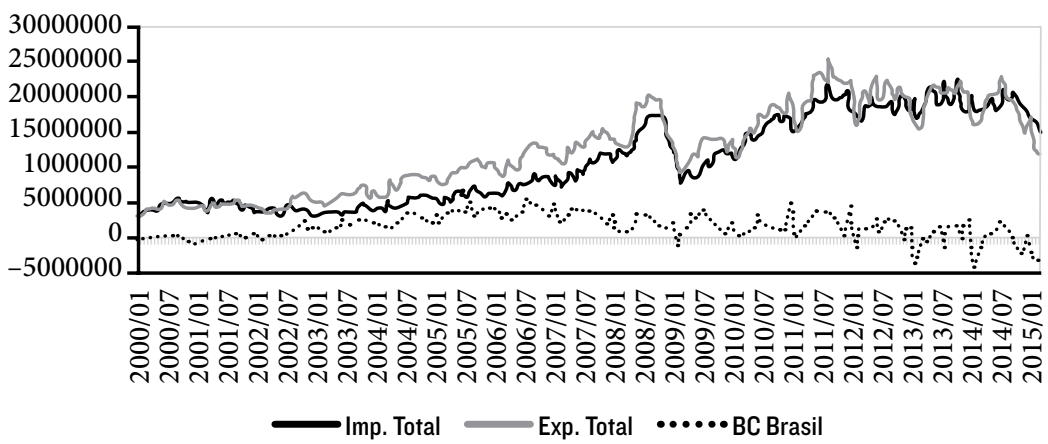

Fonte: Instituto Brasileiro de Petróleo, Gás e Biocombustíveis (IBP), 2015.

Em pormenores, o comportamento das exportações eimportações permite visualizar nitidamente três períodos distintos da balança comercial brasileira. O primeiro deles data do início da série analisada a meados de 2002 , quando os fluxos de comércio apresentaram relativo equilíbrio, resultando em um saldo comercial próximo de zero, porém positivo, à exceção do ano 2000 . Esse resultado é explicado, em grande medida, pelo baixo crescimento do comércio mundial, corroborando Salvato, Sant'Anna e Silva (2008), que observam que as taxas de crescimento do comércio mundial foram relevantes para determinar a evolução das exportações e importações nesse período (2000/2001).

O segundo período se estendeu de meados de 2002 a 2006 e mostra o descolamento das exportações, as quais cresceram persistentemente acima das importações, o que permitiu que a balança comercial atingisse os maiores valores dos anos recentes, caso de 2006 , quando o saldo positivo superou US $\$ 46,5$ bilhões. Atribui-se esse resultado, entre outros fatores, à entrada da China na Organização Mundial do Comércio (OMC), em 2001, e à aceleração de seu crescimento (Brum, 2013), como também ao crescimento do comércio em termos globais e à depreciação da taxa de câmbio. Para Salvato, Sant'Anna e Silva (2008), essa combinação de fatores puxou fortemente o aumento das exportações, fazendo com que o saldo da balança comercial crescesse expressivamente.

Já o terceiro período ocorreu a partir de 2007, com a inflexão da trajetória do saldo da balança de fluxos de comércio, decorrente do crescimento ascendente das importações, muito embora as exportações também tenham crescido, porém em menor magnitude; como consequência, o saldo comercial tem retrocedido ano após ano, atingindo em 2014 o pior resultado desde 1998, com saldo negativo de cerca de US $\$ 4$ bilhões.

Dois fatos contribuíram para isso. O primeiro relaciona-se ao vo- 
lume total das negociações comerciais externas brasileiras, que foi o menor desde 2011, e o segundo, mais diretamente relacionado ao déficit comercial, se refere às exportações, que diminuíram em ritmo mais acelerado que as importações quando comparadas com o ano de 2013 - as primeiras caíram 7,05\%, as segundas, 4,38\%. Esse comportamento teve origem na queda dos preços das commodities no mercado internacional, sobremaneira do minério de ferro, ena perda de participação dos bens industrializados nas vendas externas brasileiras, cujo recuo superou $13 \%$ (o ritmo da redução no caso dos semimanufaturados e dos básicos foi menor: $4,8 \%$ e 3,1\%, respectivamente).

Esse resultado se mostrou característico ao longo dos anos 2000, com as exportações de commodities expandindo-se em detrimento das vendas externas de produtos industrializados e semi-industrializados. Essas evidências reforçam os argumentos que apontam um processo de reprimarização das exportações (Bresser-Pereira (2008)) como também de desindustrialização em curso no Brasil (Pastore, Gazzano e Pinotti (2013); Cunha, Lelis e Fligenspan (2013)).

A balança comercial cresceu de forma progressiva entre $2002 \mathrm{e}$ 2006, para depois retrair-se, ainda que lentamente, mantendo a tendência declinante. Observa-se também sua volatilidade após 2008 , com visível comportamento sazonal no mês de janeiro; nesse mês de 2014 apurou-se o mais expressivo resultado negativo (US $\$ 4,07$ bilhões), o que consolidou o menor resultado em ano fechado das transações comerciais do Brasil com o exterior (US $\$ 4$, o bilhões) desde o ano de 1998.

Essa sazonalidade ocorreu em função da queda tanto das exportações quanto das importações no início dos anos sequentes a 2008 , porém a magnitude da retração das exportações superou a das compras externas em todos os anos. Isso corrobora o comportamento mais estável das importações ao longo do período analisado, sobretudo após a crise econômica internacional. Outra conclusão está associada ao fato de que nas importações brasileiras prevalecem produtos manufaturados (de maior intensidade tecnológica), menos sensíveis aos efeitos conjunturais, enquanto nas exportações, pelo fato de serem compostas de produtos básicos e commodities, a dinâmica econômica internacional tem efeitos mais diretos.

Ainda, conforme ressaltam Salvato, Sant'Anna e Silva (2008), as importações brasileiras aceleraram sua taxa de crescimento a partir desse período, favorecidas pelo tanto pelo câmbio apreciado como pelo aumento da demanda interna, como consequência de a elevação da renda per capita doméstica ter se apresentado mais sustentável e equilibrada. 
O resultado comercial brasileiro oriundo das compras e das vendas externas do petróleo e de seus derivados vem ganhando cada vem mais espaço nos debates econômicos e políticos, haja vista sua importância estratégica, sobretudo para os próximos anos, tanto na forma de redução da dependência externa de combustíveis como na forma de inserção internacional.

Para subsidiar tais discussões, examinou-se a evolução da conta petróleo, como também de sua composição, ao longo dos últimos quinze anos na economia brasileira. Em uma primeira parte discutem-se a evolução das exportações e das importações e o respectivo saldo comercial das contas externas do petróleo e seus derivados, além de seu relacionamento com a balança comercial brasileira (ver Figuras 2, 3 e 4). E, em parte complementar, analisa-se a composição dos fluxos de comércio da conta petróleo, conforme se observa nas Figuras 5 e 6.

As importações e as exportações brasileiras de petróleo e derivados evoluíram de forma muito próxima em praticamente todo o período analisado, com leve tendência expansionista; porém, a partir de 2010 , as vendas externas desses produtos passaram a apresentar elevada instabilidade, além de não acompanharem o comportamento das compras domésticas. Enquanto as importações mantiveram a tendência de crescimento, as exportações estagnaram em um primeiro momento e em seguida, após meados de 2011, retraíram-se continuadamente, exceto em alguns poucos períodos (ver Figura 2).

Essas evidências coincidem com a crise econômica norte-americana, iniciada em 2007, mas com consequências mais pronunciadas nas economias internacionais no ano seguinte. Esse fato determinou a retração das relações comerciais globalmente, com os países incertos quanto ao cenário econômico. Todavia, as incertezas recorrentes atingiram mais os produtos brasileiros, os quais não mantiveram o mesmo volume negociado externamente; por outro lado, as compras, embora tenham apresentado volatilidade superior à dos períodos anteriores, mantiveram a mesma tendência, com leve redução ao longo de 2014 . 
Figura 2

Exportações, importações e balança comercial do petróleo, de janeiro/2000 a fevereiro/2015, em US\$

milhões (FOB)

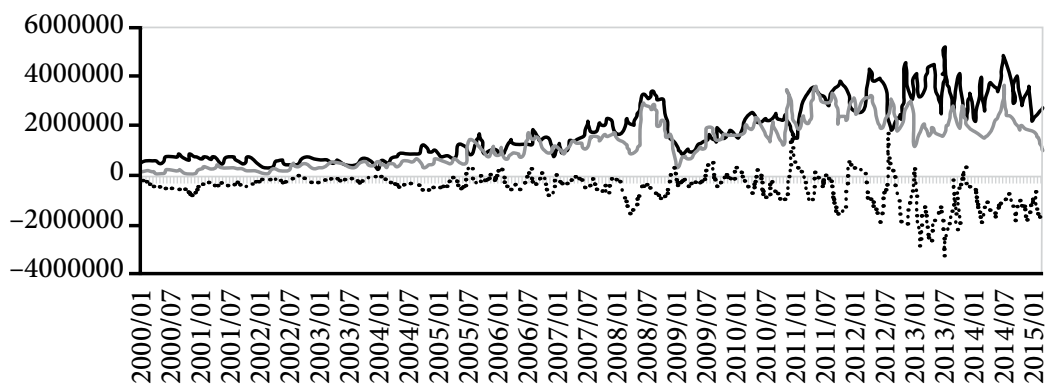

Imp. Total Pet

Exp. Total Pet

BC Brasil

Fonte: Instituto Brasileiro de Petróleo, Gás e Biocombustíveis (IBP), 2015

Concorrem para esse cenário: (i) o fato de as exportações brasileiras de petróleo e derivados serem mais sensíveis às condições econômicas externas e (ii) a crescente dependência brasileira de produtos dessa natureza (Colomer e Tavares, 2012). Isso se explica, em grande medida, pela composição da pauta exportadora e importadora. Enquanto na primeira predominam produtos derivados de petróleo (óleo combustível, combustíveis para navios e aeronaves), na segunda prevalecem o petróleo e derivados como óleo diesel e nafta.

Contudo, a relação entre o comportamento da balança comercial brasileira e o resultado da conta petróleo não parece ser estável ao longo do período analisado, haja vista que se verificam claramente três momentos distintos (ver Figura 3), similarmente ao discutido na seção anterior.

O primeiro deles ocorre entre 2000 e 2002 , quando ambas as contas evoluíram sem grandes oscilações e de forma equilibrada, exceto pela retração da balança comercial em meados de 2000 . As posições desse período refletiram, em grande medida, as mudanças na política cambial promovidas em 1999. Com o câmbio estabilizado em um nível sensivelmente mais depreciado comparativamente ao período anterior, o crescimento das importações foi acomodado, o que possibilitou a recuperação do saldo comercial brasileiro.Já o resultado comercial do petróleo e derivados, embora consistentemente negativo, sinalizava para um menor desequilíbrio, ao passo que o déficit em 2002 correspondeu a cerca de $60 \%$ do verificado em 2000 .

Salienta-se que o movimento altista dos preços do petróleo, iniciado nos anos 2000 , tem na perspectiva de esgotamento iminente das reservas petrolíferas (capacidade de produção limitada e estoques em níveis baixos) um de seus principais fatores. Contribuem também para essa dinâmica fatores cíclicos e de curto prazo, com o crescimento da demanda impulsionando a aceleração dos preços. Outros fatores 
que não devem ser desconsiderados se relacionam às mudanças estruturais na indústria do petróleo e às políticas da Organização dos Países Exportadores de Petróleo (OPEP).

O segundo momento ocorreu entre meados de 2002 e de 2006 , quando a balança comercial cresceu sistematicamente, atingindo o maior saldo positivo nesse último ano, enquanto a conta petróleo apresentou déficit em patamar similar ao do período anterior, não demostrando, assim, influenciar diretamente o resultado comercial do país. Essa expansão da balança comercial deve-se ao crescimento econômico global, bem como às exportações, que cresceram aceleradamente, registrando recordes históricos, inclusive em magnitude muito superior ao crescimento das importações. Ademais, destaca-se que esse processo ocorreu a despeito de instabilidades externas, caso do choque adverso sobre as contas externas brasileiras decorrente da crise argentina.

Por sua vez, o terceiro momento teve início depois de 2007, quando o saldo comercial brasileiro passou a deteriorar-se anualmente. Todavia, até 2013 o resultado comercial se manteve positivo, diferentemente do ano seguinte, quando, depois de treze anos, a balança comercial apresentou-se novamente deficitária, com saldo negativo da ordem de US $\$ 4$ bilhões. Nesse mesmo período, a conta petróleo mostrou acentuada volatilidade, com déficits comerciais expressivos, caso de 2008 , quando superou US $\$ 7,2$, bilhões, e dos anos de $2011 \mathrm{e}$ 2012 , quando os resultados negativos ficaram em torno dos US $\$ 5,5$ bilhões; diferentemente dos anos de 2013 e 2014, cujos déficits foram da ordem de US $\$ 0,3$ e US $\$ 2,1$ bilhões, respectivamente.

Esse resultado se explica a partirde questões tanto internas quanto externas. No primeiro caso, destaca-se o baixo crescimento do volume de petróleo refinado e da produção de derivados do petróleo, os quais se expandiram cerca de $2,85 \%$ e 2,90\% ao ano, respectivamente, quando considerado o intervalo 2000-2014. Nessa linha, Colomer e Tavares (2012) afirmam que é de fundamental importância a ampliação da capacidade de processamento de petróleo; contudo, para que isso ocorra faz-se necessária uma reformulação na atual política interna de preços, com o objetivo de atrair novos investimentos para o segmento de refino. Por seu turno, esse cenário tem contribuído para o aumento da dependência brasileira da importação de combustíveis e derivados.

Todavia, cabe ressaltar que a receita das exportações de produtos derivados do petróleo cresceu significativamente (mesmo com a produção crescendo em ritmo menor), porém não o suficiente para acompanhar o crescimento das importações domésticas. Nesse tocante, o maior consumo doméstico de petróleo e derivados, para uso em diversos fatores, correspondeu a parcela significativa desse crescimento. 
Acresce-se a isso o aumento do dispêndio com as importações de gás natural.

Por outro lado, salientamos que o comportamento da produção de petróleo no Brasil reflete a influência não somente dos preços, mas também de outros fatores, sejam eles de natureza estratégica ou política, conforme destacado em relatório da $\mathrm{CNI}$ (2012), dentre os quais: o interesse em garantir a segurança do suprimento de um insumo essencial e majoritariamente produzido, em nível mundial, em regiões política e socialmente instáveis; o impacto positivo da produção nacional em praticamente todas as atividades econômicas; e os efeitos positivos sobre a balança comercial, decorrentes tanto da redução das importações quanto da possibilidade de exportação de petróleo.

No que tange às questões externas, destaca-se o comportamento volátil do preço do barril de petróleo nos últimos quinze anos, em um movimento similar àquele observado na balança comercial da commodity no Brasil. O expressivo crescimento entre os anos de 2000 e 2008 , quando o valor do barril passou dos US $\$ 28$ para US $\$$ 110 , coincidiu com a expansão dos déficits comerciais brasileiros, evidência que é corroborada pelo deslocamento crescente das importações, movimento que foi interrompido em 2008 , quando o barril chegou a recuar 60\% (Prates, 2011) em decorrência da crise financeira internacional e, consequentemente, da redução da atividade econômica global.

Contudo, um novo impulso verificou-se entre 2009 e meados de 2013, quando o preço do barril superou novamente a barreira dos US\$ 100, permanecendo nesse nível por consecutivos períodos. Porém, os meses finais de 2014 têm mostrado nova inversão, em um movimento acentuadamente descendente do preço do petróleo, com o barril sendo negociado, em média, a US\$70 (FMI, 2015).

Esse declínio recente do preço do barril tem na mudança de posicionamento dos Estados Unidos quanto às importações globais de petróleo o principal fator. Tal mudança está relacionada à expansão da produção doméstica de combustível, sobremaneira de óleo xisto. $\mathrm{Na}$ última década (2004-2013), a produção norte-americana elevou-se em praticamente $40 \%$, enquanto as importações vêm se reduzindo sistematicamente (15\% nos últimos cinco anos), com destaque para aquelas oriundas dos países da OPEP(IBP, 2015).

Além disso, tem-se observado o declínio da demanda de petróleo pelos países europeus, que, conforme Prates (2011), se revelou mais fraca como reflexo do ritmo insuficiente da atividade econômica - o agravamento da crise soberana da área do euro desencadeou movimentos de natureza financeira que, em conjunto, foram responsáveis pela queda dos preços das commodities - e da maior eficiência energética dos novos modelos de automóveis. Na contramão desses movimentos, a OPEP 
tem mantido a produção em níveis elevados, o que tem gerado excesso de oferta e pressionado ainda mais os preços para baixo.

\section{Figura 3}

Evolução do saldo da balança comercial e da balança comercial brasileira do petróleo entre janeiro/2000 e fevereiro/2015, em US\$ milhões (FOB)

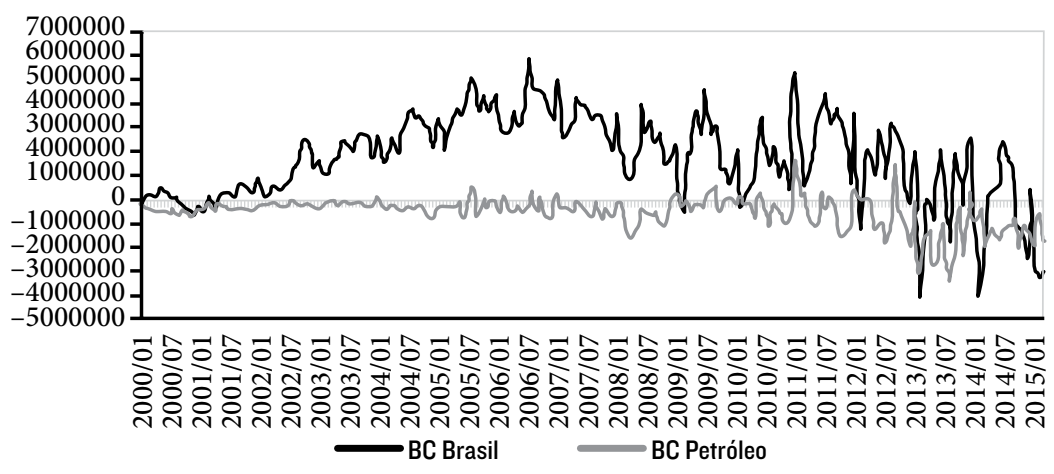

Fonte: Instituto Brasileiro de Petróleo, Gás e Biocombustíveis (IBP), 2015.

De forma complementar, buscando extrair evidências adicionais quanto à relação da conta petróleo e do saldo comercial externo, excluiu-se o resultado da conta petróleo da balança comercial brasileira, o que possibilitou examinar o comportamento das contas externas sem o efeito direto dos combustíveis e derivados (ver Figura 4). Tal procedimento permitiu verificar comportamentos característicos e distintos daqueles anteriormente observados.

Do início do período a 2008 evidencia-se trajetória similar para a balança comercial brasileira com e sem o resultado da conta petróleo,e nesse período o resultado comercial do petróleo e derivados manteve-se deficitário, porém apresentando relativa estabilidade. A partir de 2005, verifica-se maior volatilidade na conta de combustíveis e derivados, contudo sem reflexos claramente observáveis sobre o comportamento do balanço de comércio.

\section{Figura 4}

Balança comercial brasileira, balança comercial do petróleo e balança comercial brasileira sem a conta petróleo, entre 2000 e 2013, em US\$ milhões (FOB)

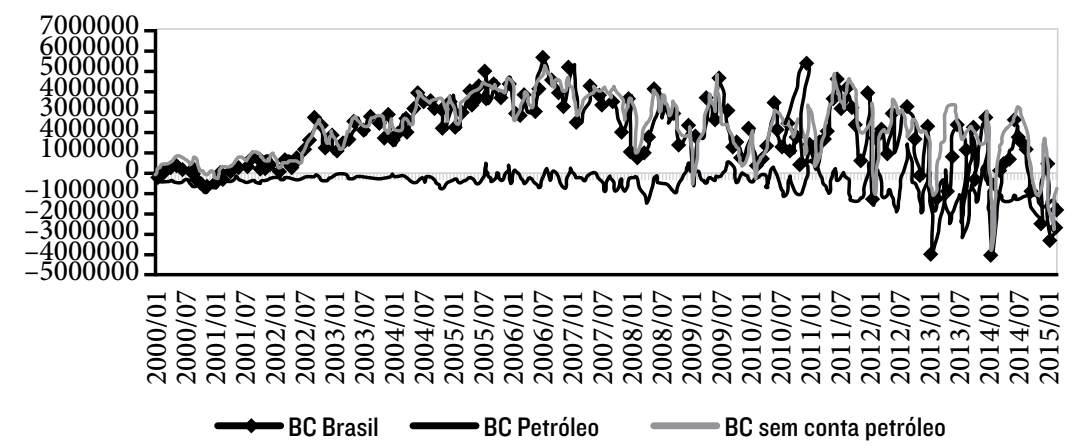

Fonte: Instituto Brasileiro de Petróleo, Gás e Biocombustíveis (IBP), 2015. 
[3] Compõem a conta de derivados: asfalto, combustivel para aeronaves, combustível para navios, coque, gasolina A, gasolina para aviação, gás liquefeito de petróleo, lubrificante, nafta, óleo combustível, óleo diesel, outros não energéticos, parafina, querosene de aviação, querosene iluminante e solvente (IBP, 2014).
Visualiza-se comportamento distinto no período posterior a 2008 , com a conta petróleo apresentando sucessivas e significativas alterações, as quais vêm acompanhadas do agravamento do saldo negativo - situação que tem encontrado correspondência no comportamento da balança comercial: aumento da volatilidade e tendência declinante. Logo, infere-se que a balança comercial com a conta petróleo incluída tem reproduzido os movimentos originados nas relações de comércio do petróleo e derivados no período recente, enquanto a balança comercial com a exclusão do saldo dos combustíveis tem demonstrado comportamento mais suavizado, indicativo de que os demais fluxos de comércio têm refletido, em grande medida, as condições de mercado.

Contudo, ressalte-se que não se podem desconsiderar os efeitos indiretos das exportações e importações de petróleo e derivados sobre o balanço de comércio do país, haja vista que os setores de bens transacionáveis tendem a incorporar tal comportamento. Isso implica aferir que a balança comercial sem a conta petróleo pode ainda reproduzir parcialmente os efeitos da conta petróleo.

Complementando a análise, as Figuras 5 e 6 apresentam o comportamento da composição das exportações e das importações de petróleo e derivados no Brasil. Em específico, a conta petróleo compõe-se dos saldos das transações comerciais do petróleo, dos derivados 3 e do gás natural. No entanto, observa-se que as exportações brasileiras se restringem ao petróleo e aos derivados, enquanto as importações, além desses dois grupos, incluem o gás natural.

Ao analisar a evolução dos grupos de exportação, verifica-se que há uma tendência declinante dos derivados do petróleo em praticamente todo o período.A exceção ocorreu entre meados de 2012 e 2013 , quando as vendas externas passaram a apresentar leve expansão. No início dos anos 2000,0 Brasil exportava somente derivados de petróleo, enquanto em 2014 a participação desses produtos atingiu cerca de $48 \%$. Por outro lado, a participação das exportações de petróleo em bruto cresceu sistematicamente do início do período até 2011, para depois retrair-se até o final de 2013, porém retomou a trajetória crescente em 2014.

A queda dos derivados foi puxada, em parte, pela queda das exportações de gasolina A, que representavam cerca de $20 \%$ até 2008 , retraindo-se cerca de $75 \%$ nos anos posteriores. Da mesma forma, os combustíveis para navios, cuja participação média no período foi de $25 \%$, configuraram-se como outro produto que perdeu participação a partir de 2008 , porém em magnitude menor. Contudo, o crescimento das exportações de óleos combustíveis, que nos anos recentes foram responsáveis por aproximadamente $37 \%$ do total, atenuou o resultado negativo da balança comercial da conta petróleo. Do lado das ex- 
portações, o crescimento foi beneficiado internamente pela expansão da produção e externamente pelo aumento dos preços no mercado internacional, à exceção dos períodos de instabilidade econômica (2008/2009) e da segunda metade de 2014, e pela demanda asiática, sobremaneira, da China.

Essa mudança na composição das exportações brasileiras se deve a um conjunto de transformações estruturais e institucionais que, a partir da segunda metade da década de 1990 , criou um novo ambiente econômico para a indústria do petróleo e derivados, com menor participação do Estado, conforme discutem Kupfer et al. (2000). Nessa esteira, as recentes descobertas, a quebra do monopólio estatal4 $\mathrm{e}$ os crescentes investimentos na exploração e no refino alavancaram a atividade petrolífera no Brasil. Todavia, faz-se importante mencionar que, com a descoberta das novas áreas de exploração (reservas do pré-sal), as quais têm grande potencial produtivo e petróleo de qualidade superior, uma série de discussões a respeito da permanência do modelo anterior, de concessão (mediante licitação em leilões abertos a empresas públicas e privadas), foi realizada, culminando na adoção do modelo de partilha para exploração e produção de petróleo.

Entre as alterações trazidas por esse marco regulatório, está a ampliação da influência da Petrobras no setor petrolífero, dado que ele facultou à União o direito de contratar diretamente a estatal, sem necessidade de licitação prévia. Além disso, Ribeiro (2011) enfatiza queà Petrobras caberá o papel de operadora única dos blocos, o que significa que a empresa será o ente responsável pelas atividades de exploração, desenvolvimento e produção das áreas em sistema de partilha.

\section{Figura 5}

Participação dos produtos (petróleo, derivados e gás natural) no total exportado da conta petróleo, entre janeiro/2000 e fevereiro/2015, em \%

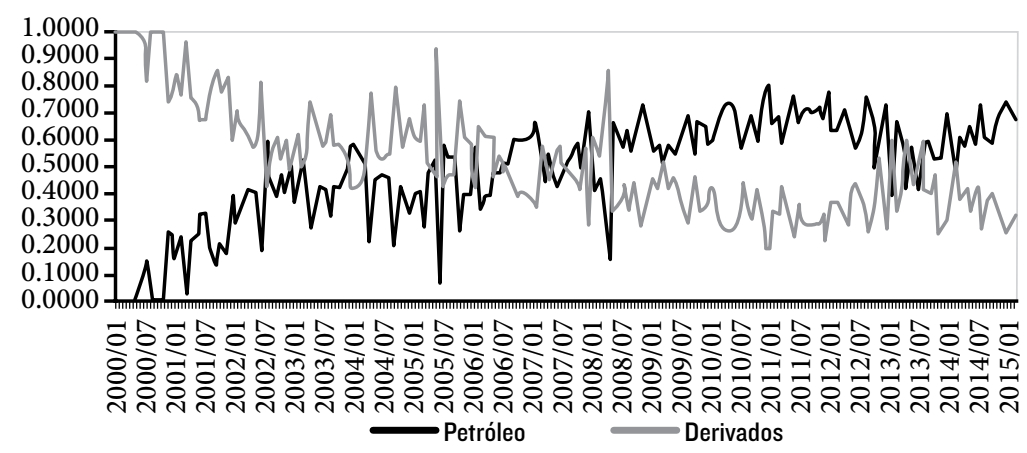

Fonte: Instituto Brasileiro de Petróleo, Gás e Biocombustíveis (IBP), 2015.

$\mathrm{Na}$ composição das importações brasileiras, observa-se que o petróleo cru (leve) continua sendo o produto mais comercializado externamente, embora sua participação ao longo dos anos recentes tenha

\begin{abstract}
[4] A lei 9.478, de 1997, estabelece que, além da Petrobrás, outras empresas constituídas sob as leis brasileiras e com sede no Brasil passem a atuar em todos os elos da cadeia do petróleo (exploração, produção, refino e transporte de petróleo).
\end{abstract}


declinado, sobretudo a partir de 2005 . Contudo, ainda cerca de $40 \%$ do saldo total das importações do país têm origem nas compras externas desse tipo de petróleo.

Já os derivados do petróleo apresentaram comportamento oposto, com leve tendência de queda até 2003 e posterior crescimento, tendo atingido no final de 2014 participação superior a $48 \%$ do saldo total das importações, superando inclusive as compras de petróleo em alguns meses dos anos recentes (a partir de 2010). Esse resultado se deve a um conjunto de fatores, entre eles o aumento dos preços, caso do etanol usado como combustível em veículos flex, ocasionado pela menor oferta do combustível no mercado doméstico (decorrente do aumento das exportações de açúcar), o que levou à necessidade de importação de gasolina.

Outros derivados, como querosene de aviação, gás liquefeito de petróleo e óleo diesel, apresentaram crescimento expressivo nos anos recentes, sobremaneira o óleo, que, sozinho, representou aproximadamente $36,5 \%$ das importações brasileiras de derivados entre 2000 e 2014. Quando considerados os últimos três anos, a participação supera os $39 \%$ do total do dispêndio com derivados de petróleo. Esse resultado encontra sustentação quando discutido o fato de que no Brasil o consumo de petróleo é determinado pela demanda doméstica de diesel, combustível utilizado predominantemente no transporte tanto de passageiros quanto de cargas (CNI, 2012). Associa-se a isso o crescimento da demanda interna, sustentado principalmente por políticas de estímulo ao consumo.

Figura 6

Participação dos produtos (petróleo, derivados e gás natural) no total importado da conta petróleo, entre janeiro/2000 e fevereiro/2015, em \%

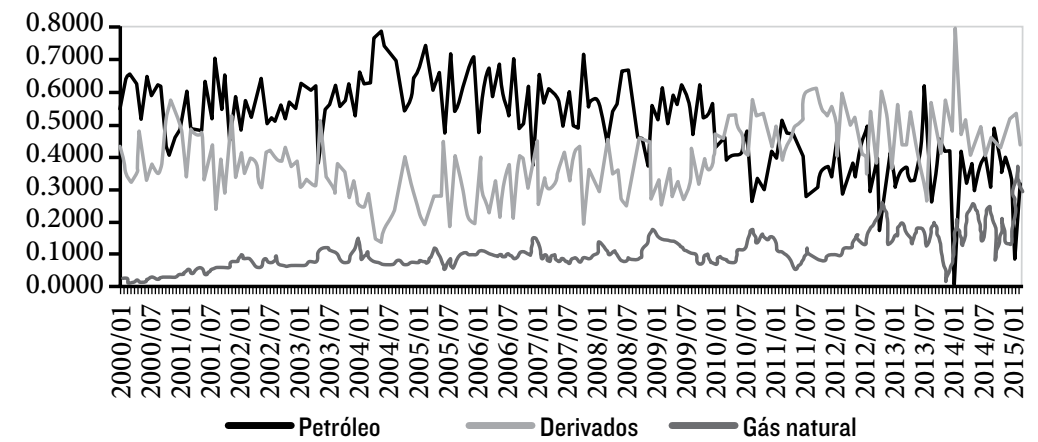

Fonte: Instituto Brasileiro de Petróleo, Gás e Biocombustíveis (IBP), 2015

No que tange ao gás natural, verifica-se um comportamento de crescimento ao longo do período. No início dos anos 2000 o dispêndio total com gás natural não superava 3,0\% do total das importações da conta petróleo, enquanto em 2014 essa participação elevou-se para 
patamares próximos de $17 \%$. Esse crescimento se deu em um contexto de expansão substantiva do preço (que passou de US $\$ 13,10$ para US $\$$ 66,50 o barril equivalente de petróleo), reflexo das elevações do preço do petróleo e da diversificação da matriz energética global (Tiryaki et al., 2008).

Quando a análise é feita em termos de volume, tem-se uma expansão mais substantiva ainda, dado que as importações cresceram a uma taxa anual superior a 15\% nos últimos quinze anos, atingindo em 2014 aproximadamente 110 milhões de barris equivalentes de petróleo (ANP, 2015). Essa expansão foi impulsionada principalmente pelo início da operação do gasoduto Brasil-Bolívia (Gasbol), em julho de 1999, o que fez elevar a participação das importações na oferta brasileira de gás natural. Com isso, conforme Prates et al. (2006), foi possível complementar a produção nacional rapidamente e em grandes volumes.

Por fim, na observação do comportamento da composição dos fluxos comerciais de petróleo e derivados destaca-se o crescimento das exportações de petróleo e derivados, porém em magnitude inferior à expansão das importações de combustíveis e derivados. Logo, em muitos períodos, constatou-se que o aumento das despesas reduziu o impacto da expansão das vendas externas de petróleo e derivados sobre o saldo da balança comercial brasileira.

Além disso, a elevada concentração dos derivados de petróleo, sobretudo nas exportações brasileiras, cuja participação no total comercializado ainda está em níveis próximos de 40\%, torna-se outro fator de potencial impacto no resultado comercial externo, pois tende a amplificar os efeitos sobre o saldo da conta petróleo em decorrência de mudanças nas condições externas.

\section{CONCLUSÕES}

O objetivo central deste artigo consistiu em discutir as relações externas de comércio do petróleo e derivados e como os resultados recentes têm impactado o resultado da balança comercial brasileira em um contexto ambíguo e difuso, tendo, de um lado, o aumento da dependência externa de petróleo e derivados, pela ampliação do déficit da conta petróleo, e, de outro, a perspectiva de expansão da produção doméstica.

As análises permitem observar a intensificação da relação entre saldo da conta petróleo e saldo comercial, com o resultado das relações comerciais de combustíveis tendo reflexos cada vez mais expressivos sobre a balança comercial, sobremaneira em um cenário mais contido para as commodities, não havendo, assim, o efeito compensador dos produtos do setor agrícola e agropecuário. 
Contudo, ao longo do período examinado não se constatou relação estável, sendo a instabilidade intensificada a partir da crise econômica internacional de 2008. Nesse período, o comportamento volátil da conta petróleo, consubstanciado no agravamento do saldo negativo, em alguma medida, tem sido absorvido pela balança comercial do país, em um efeito transferência. Isso foi corroborado pelo fato de a dependência doméstica aumentar em um cenário de expansão internacional dos preços das fontes energéticas, atenuando assim o recente crescimento das exportações brasileiras de petróleo e derivados.

A relevância atribuída ao setor de combustíveis no Brasil é de longa data e sustenta-se pela necessidade de importação desses produtos, sendo, em muitas ocasiões, os preços dos combustíveis usados como instrumento de política econômica, com a finalidade de incentivar o crescimento e/ou como forma de controlar os preços domésticos; porém, as recentes descobertas e a possibilidade de autossuficiência a médio ou longo prazo têm fornecido um novo cenário.

Nesses termos, este texto cumpre o propósito preambular de apresentar uma detalhada descrição acerca do comportamento da conta petróleo e das contas externas brasileiras no período recente. Todavia, dada a relevância do segmento de combustíveis para o país, tanto atual quanto futura, tal debate encontra largo campo para discussão. Nesse sentido, sugerem-se novos estudos com enfoque seja no mercado interno, considerando as características e políticas domésticas para o setor, seja no externo, considerando as decisões econômicas e comerciais dos principais players internacionais e seus efeitos sobre a economia brasileira.

\section{REFERÊNCIAS BIBLIOGRÁFICAS}

Agência Nacional do Petróleo (ANP). Importações e exportações (barris equivalente petróleo). Disponível em: 〈www.anp.gov. $\mathrm{br} / ? \mathrm{dw}=8475>$. Acessado em $20 / 4 / 2015$.

Bello, T.S. Déficit em transações correntes: o retorno. Fundação de Economia e Estatística (FEE), 2010 (Textos para discussão $n^{\circ} 75$ ).

Bresser-Pereira, L.C. "The Dutch disease and its neutralization: a Ricardian approach". Revista de Economia Política, v. $28, \mathrm{n}^{\circ}$ 1, 2008.

Brum, D.M. A deterioração recente nas transações correntes brasileiras. Comentário macroeconômico, 2013. Disponível em: 〈http:// www.opportunitydtvm.com.br/documentos/PDF_Comentario/ cm201305.pdf .Acessado em 14/3/2014.

Colomer, M., e Tavares, A. Precificação de combustíveis no Brasil e as barreiras ao investimento. Grupo de Economia da Energia, 2012. Disponível em: 〈http://www.gee.ie.ufrj.br/arquivos/publicacoes ceee/TD_gee_ibp_oo4_Colomer_Tavares.pdf $>$. Acessado em 29/3/2014. 
Confederação Nacional da Indústria (CNI). Contribuição do setor brasileiro de petróleo, gás e biocombustiveis para o desenvolvimento sustentável no país. Brasília: CNI, 2012 (Cadernos setoriais Rio+20).

Cunha, A.M., Lelis, M.T.C., e Fligespan, F.B. “Desindustrialização e comércio exterior: evidências recentes para o Brasil". Revista de Economia Política, v. 33, $\mathrm{n}^{\circ} 3, \mathrm{pp} .463-485,2013$.

Instituto Brasileiro de Petróleo, Gás e Biocombustíveis (IBP). Informações e estatísticas da indústria. Disponível em: 〈http://200.189.102.61/SIEE/dashboard/ImportExportOfPetroleumNaturalGasAndByProducts $>$. Acessado em 5/1/2014. . Comércio de petróleo e seus derivados. Disponível em: 〈http://www.ibp.org.br〉. Acessado em 5/1/2014. . Importação e exportação de petróleo e derivados. Disponível em: 〈http://200.189.102.61/SIEE/dashboard/ EstatisticasInternacionaisImportacaoEExportacao>. Acessado em $19 / 4 / 2015$.

International Monetary Fund. International Financial Statistics - Petroleum. Disponível em: 〈http://elibrary-data.imf.org〉. Acessado em $16 / 4 / 2015$.

Kupfer, D., Haguenauer, L., Young, C.E., e Dantas, A. Impacto econômico da expansão da indústria do petróleo. Convênio IE/UFRJ/ ONIP, Infopetro - Sistema de Informações Econômicas sobre o setor petróleo, 2000.

Pastore, A.C., Gazzano, M., e Pinotti, M.C. "Por que a produção indústria não cresce desde 2010?”. In: Bacha, E., e Bolle, M. (eds.).O futuro da indústria no Brasil: desindustrialização em debate. Rio de Janeiro: Civilização Brasileira, 2013.

Prates, D.M. "O novo ciclo de preços das commodities". Boletim de Economia. Fundap, $\mathrm{n}^{\mathrm{O}} 2$, março 2011 . Disponível em: 〈http://www. fundap.sp.gov.br/wp-content/uploads/2014/o3/boletim_economia_12_setorial_a_deflacao_dos_precos_das_commodities.pdf..Acessado em 18/4/2015.

Prates, C.P.T., Pierobon, E.C., Costa, R.C., e Figueiredo, V.S. “Evolução da oferta e da demanda de gás natural no Brasil”. BNDES Setorial. Rio de Janeiro, $\mathrm{n}^{\circ} 24, \mathrm{pp} \cdot 35-68,2006$.

Ribeiro, T.M. "O pré-sal e as mudanças no marco regulatório do petróleo". Boletim de Economia. Fundap, n 5 , junho 2011. Disponível em: 〈http://www.fundap.sp.gov.br/wp-content/uploads/2014/o3/ boletim_economia_5_setorial__pre-sal.pdf $>$. Acessado em $18 / 4 / 2015$. 
Recebido para publicaçao em 22 de

abril de 2015 .

\section{NOVOS ESTUDOS}

CEBRAP

101, março 2015

pp. 79-95

Salvato, M.A.,Sant'anna,P.H.,e Silva, L.A.G. “Evolução da balança comercial brasileira no período de câmbio flutuante". Economia \& Tecnologia, v. 13, pp. 5-18, abril-junho, 2008.

Tiryaki, G.F., Sanchez, F.F., Silva, G.F. da, Gomes, J.L., e Santos, E. "Flexibilização da oferta de gás natural para a Bahia". Revista Econômica do Nordeste. Fortaleza, v.39, n ${ }^{\circ}$, out.-dez., 2008.

REISOLI BENDER FilHo é professor do Departamento de Ciências Administrativas e do Programa de Pós-Graduação em Administração da Universidade Federal de Santa Maria - UFSM. 